\title{
Comparison the Performance Evaluation of Xgpon-Rof System with Wdm and Scm for Different Modulation Schemes
}

\author{
Muntadhar H. Ismeala ${ }^{a}$, Bashar J. Hamzaa $^{a}$, Wasan Kadhim Saada ${ }^{a}$ \\ ${ }^{a}$ Department of communication technical engineering, al-furat al-awsat technical University, alnajaf, Iraq.
}

\begin{tabular}{l} 
A R T I C LE IN F O \\
\hline Article history: \\
Received 01 November 2019 \\
Received in revised form 20 October 2019 \\
Accepted 31 October 2019 \\
\hline Keywords: \\
XGPON \\
BER \\
RoF \\
SRm \\
WDM \\
SCM
\end{tabular}

\begin{abstract}
A B S T R A C T
At the present time and as a result to the recent developed technology demand for higher data rate and capacity has been increased. For the wireless networks, the combination of radio over fiber (RoF) with (XGPON) Gigabit-capable PON techniques produce a high data rate at lower cost. Thus, this paper illustrates that the performance of RoF-XGPON optical link has been analyzed for multi-channel through combining two multiplexing techniques, such as; Subcarrier Multiplexing (SCM) and Wavelength Division Multiplexing (WDM). The proposed system utilizes WDM-xGPON and SCM-XGPON architecture combined with RoF technology with $10 \mathrm{Gpbs}$ data rate and (2.4, 5.8, 10 and 15) GHz radio frequency (RF), when change the optical fiber length between (10 to 80$) \mathrm{km}$. The network performance is compared with various digital quadrate amplitude modulation schemes, like ; 4 - QAM, 16 - QAM and 64 - QAM for various input power $(-2,2$, and 6$) \mathrm{dB}$. The performance analysis is based on the optical spectrum of transmitted and received signals for 4-channel, constellation diagram, eye diagram, bit error rate (BER), power received, and quality factor. The result explain that the WDM-XGPON-Rof performs better than SCM-XGPON-Rof for different modulation schemes. The bit error rate for WDM-XGPON less than the SCM-XGPON while the power received recorded to the WDM-XGPON greater than SCM-XGPON and the quality factor for SCM-XGPON less than the WDM-XGPON. Therefore The simulation results show that the WDM-XGPON-RoF gives better performance from SCM-XGPON-RoF. The software optisystem version 15 has been used to simulate this system
\end{abstract}

\section{Introduction}

RoF is one of the most important applications in fiber optic system. In RoF, light is set to a radio frequency and transmitted over fiber optics for easy wireless access . Technically, RoF is a hybrid system that combines

\footnotetext{
* Corresponding author.

E-mail address: muntadernajaf@gmail.com (Muntadhar H. Ismeala)
}

https://doi.org/10.30772/qjes.v12i4.240

2411-7773/@ 2019 University of Al-Qadisiyah. All rights reserved.

wireless and optical in one system leading to high capacity, high data rate, transparent and mobile solutions [1]. RoF networks allow customers to retain their traffic while also providing them with the necessary bandwidth 
for current and future connections [2]. Passive Optical Network (PON) A network with multiple optical fibers and a variety of broadband services [3]. PON remove all active components between the client and the server. This is done by introducing passive optical components to route traffic over the network. The passive optical network acts as a transmission device between OLT and various ONT through optical subdivisions, which removes multiplex or multiplex signals by destination and origin. Therefore, the network has three devices: OLT, ONT and splitter, and each has its own function on the passive optical network which is necessary. XGPON is a variant of PON technology which can support higher data rate (10 Gbps) using a point to multipoint access mechanism. A XGPON system is a point-to-multipoint network architecture deploying optical access lines between a carrier's central office and customer sites [4]. The major advantage of using XGPON standard that is its more speed as compared too other PON standards. It is observed that XGPON bandwidth $10 \mathrm{Gbits} / \mathrm{s}$ for individually subscriber. The RoF system is integrating wireless and fiber based technology. The main objective of the RoF system is to distribute broadband signals to distributed base stations for wireless access using an optical access network[12]. The PON combination with RoF technology provides a high capacity solution and high data rate[10]. Waveform Division Multiplexing (WDM) The basic concept of WDM technology is to combine multi-channel optical with different wavelengths that come from different optical sources to a single fiber through multiple transmitters used on the sender side as well as multiplexer removal tools on the side of the receiver to split WDM channels[11]. However, WDM is an effective method that can be used in the fiber optic feeder network to increase the capacity of RoF systems, increase the usable fiber bandwidth and increase the number of base stations supported by the central office [5,6]. Subcarrier Multiplexing (SCM) technology is one of the multicast technologies that can be used in the optical system to increase bandwidth efficiency. SCM is more sensitive to noise effects, limiting data rates and maximum sub-carrier frequencies[8,9]. Optical sub-carrier multiplexing (OSM) is a system in which more than one signal is transmitted in the radio frequency field and then transmitted through the use of a single wavelength[7]. In this paper, we analyze and compare between RoF-XGPON-WDM and RoF-XGPONSCM system regarding parameters such as transmission distance, eye diagram, power, Q factor and BER. It shows the RoF-XGPON-WDM is more energy efficient and transmits data at long distance with low losses and best BER as compared to the RoF - XGPON-SCM. the systems performance is analyzed on the basis of variation of factors such as quality factor, eye diagram and minimum BER using 15 optisystem.

\section{System Design}

The main goal of this paper is to investigate the intergration of RoF with XGPON. The system design as shown in Fig. 1. includes four main parts which are transmitter, fiber channel, Splitter and receiver. Used as a source of data with $10 \mathrm{Gbps}$ of data rate the Pseudo-Random Bit Sequence Generator (PRBS). The QAM sequence generator utilized as QAM modulator for the data rate. Band-pass filter (BPF) utilized at both transmitter and receiver to get the detecated spectrum. The Mach-Zehnder Modulator (MZM) used as optical modulator which modulate the radio signal over light signal that generated by Continuous Wave laser (with 1500 $\mathrm{nm}$ of wavelength). The Splitter 1x32 device splits evenly the signal input power to 32 output ports. At the receiver side, after photodetection by Positive-Intrinsic-Negative (PIN), Filter the signal and amplify it to regenerate the required signal. The signal then fed into bit error rate (BER) analyzer and the spectrum for data analysis.

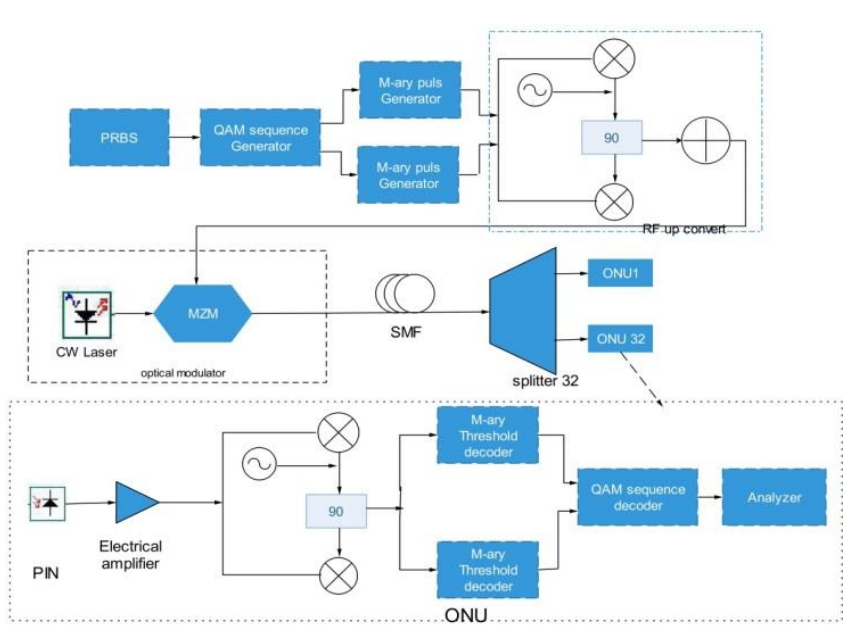

Figure 1. RoF-XGPON system design

However, 4-RF channels (2.4 GHz, $5.8 \mathrm{GHz}, 10 \mathrm{GHz}$ and $15 \mathrm{GHz})$ are simulated through used (4-QAM,16-QAM and 64-QAM) modulation techniques. The proposed simulation setup model for the SCM-XGPONRoF system is shown in Fig. 2.
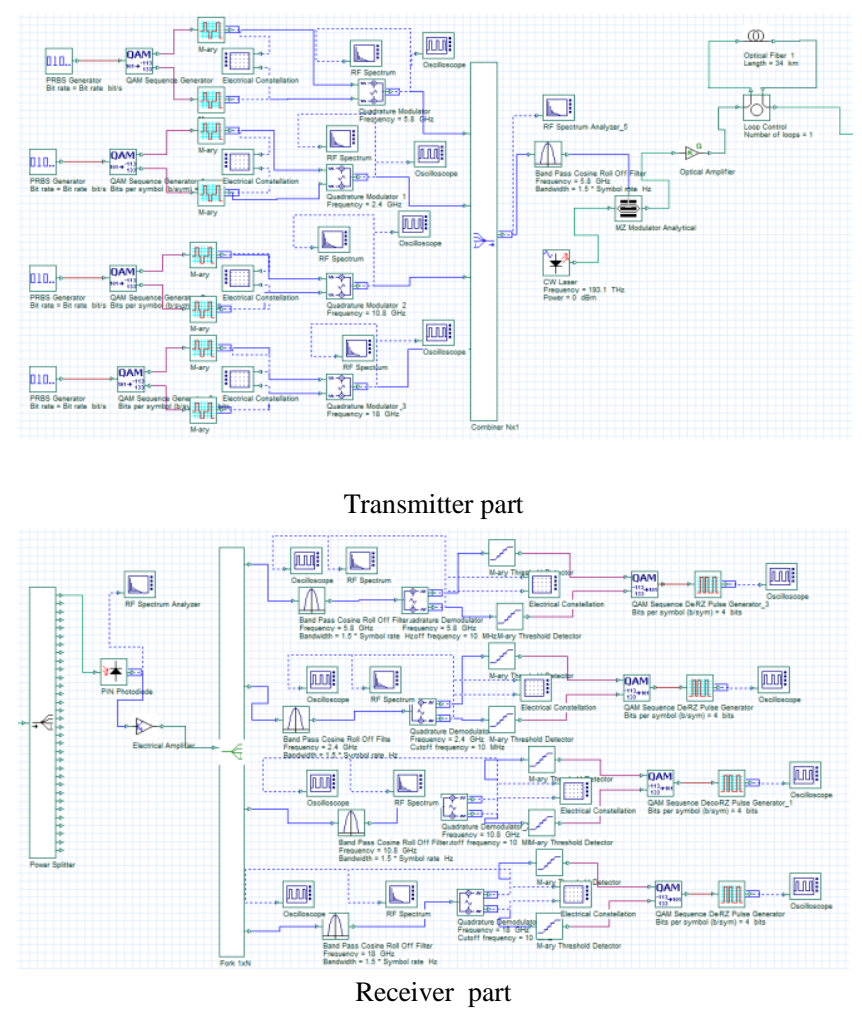

Figure 2. simulation setup model for the SCM-XGPON-RoF system

channels with different wavelengths coming from different optical sources into a single fiber using multiplexers at the transmitter end and demultiplexers in the receiver to split WDM channels, which are simulates through use different modulation techniques. The proposed simulation setup for the WDM - XGPON-RoF model shown in Fig. 3. 


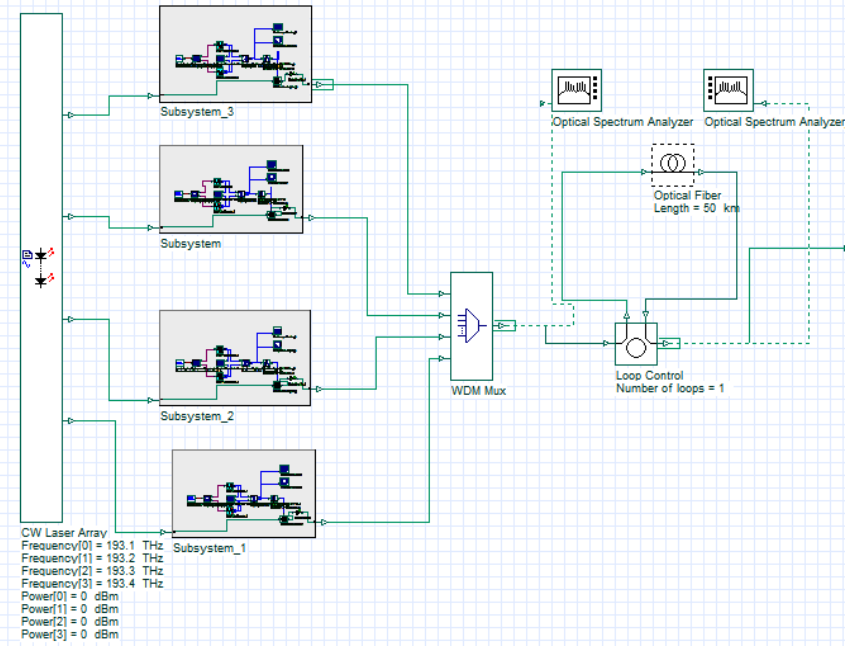

Transmitter part for WDM-XGPON

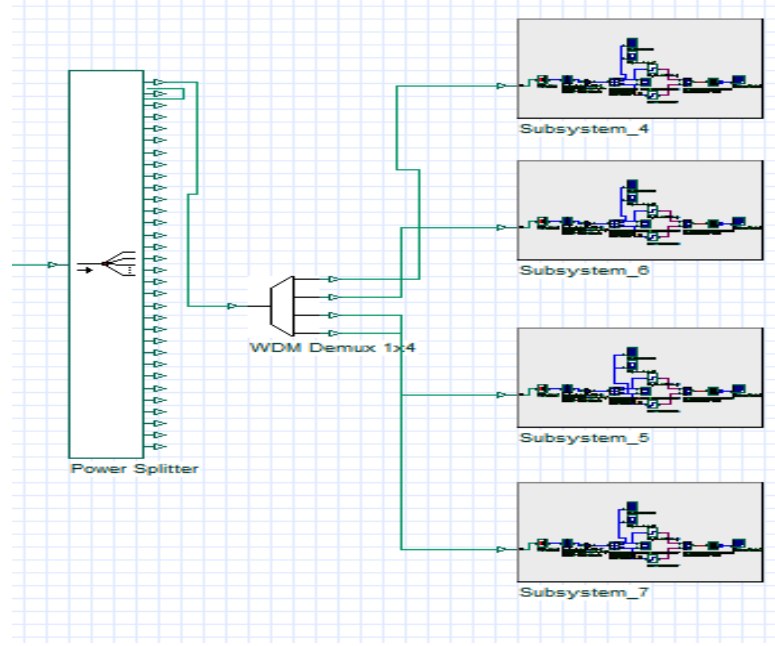

Receiver part for WDM-XGPON

Figure 3. simulation setup model for the WDM-XGPON-RoF system

\section{Result and Discussion}

The performance of the proposed system depended on many factor like eye diagram, BER, quality factor, power and constellation diagram. To compare the performance of SCM-XGPON-RoF system with WDMXGPON-RoF. The relation between max. Q factor and BER.

Figs. 4 and 5 shows received constellation diagram for the SCMXGPON and WDM-XGPON, respectively, after $50 \mathrm{~km}$. The distortion in the signal at the receiver is increased in SCM-XGPON system greater than WDM-XGPON



a.4-OAM SCM-XGPON

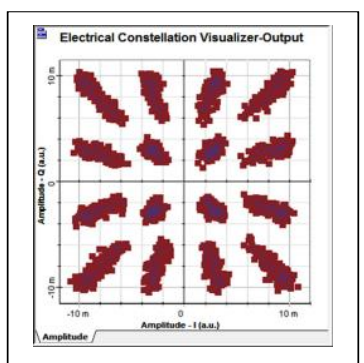

b.16-OAM SCM-XGPON



c.64-QAM SCM-XGPON

Figure (4) constellation diagram for the SCM-XGPONRoF system model for different modulation scheme

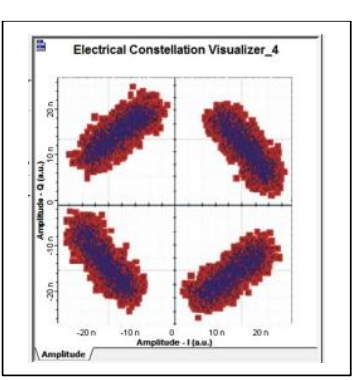

a.4-OAM WDM-XGPON

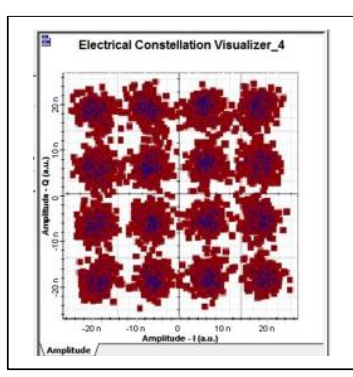

b.16-OAM WDM-XGPON

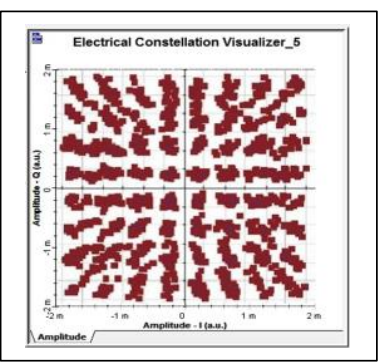

c.64-QAM WDM-XGPON

Figure (5) constellation diagram for the WDM-XGPONRoF system model for different modulation scheme 
Figs. 6 and 7 shows the eye diagram for the SCM-XGPON and WDMXGPON after $50 \mathrm{~km}$. The shown the signal quality high speed digital transmission. The eye diagram for WDM-XGPON clear and open is better than SCM-XGPON.

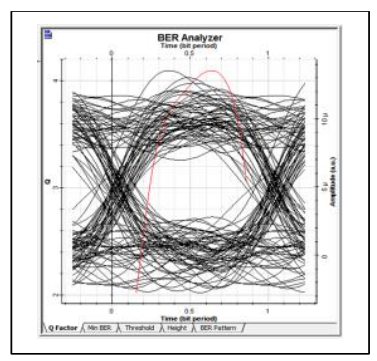

a.4-OAM SCM-XGPON

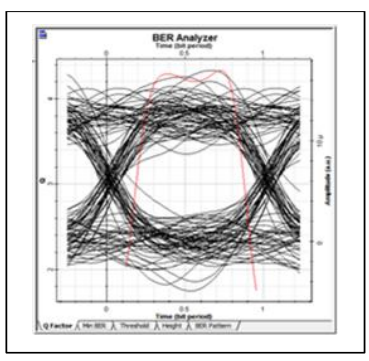

b.16-OAM SCM-XGPON

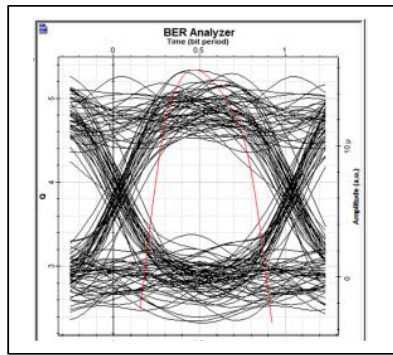

c.64-QAM SCM-XGPON

Figure (6) eye diagram for the SCM-XGPON-RoF system model for different modulation scheme

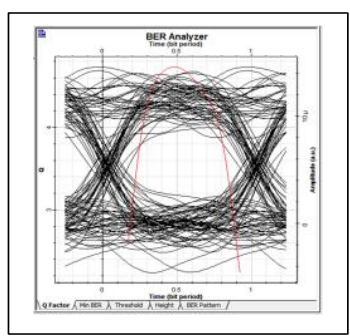

a.4-OAM WDM-XGPON

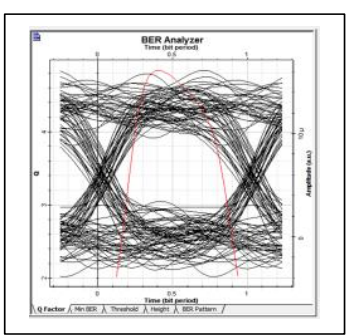

b.16-OAM WDM-XGPON



c.64-QAM WDM-XGPON

Figure (7) eye diagram for the WDM-XGPON-RoF system model for different modulation scheme
Figs. 8 and 9. shows the opposite of BER with the length of optical fiber length. The distance from $10 \mathrm{~km}$ to $80 \mathrm{~km}$. The BER increase when the fiber length is increase. The system WDM-XGPON obtained a good results because the BER less than SCM-XGPON. The 64-QAM for WDM at $49 \mathrm{~km}$ the bit error rate less than 10-9 [10] acceptable level while the BER for 64-QAM for SCM less than 10-9 at $46 \mathrm{~km}$.



Figure (8) BER versus length of fiber for SCM-XGPON



Figure (9) BER versus length of fiber for WDM-XGPON

This variation of power received with fiber has been for three types of modulation 4-QAM, 16-QAM and 64-QAM shows in Figs. 10 and 11 for SCM-XGPON and WDM-XGPON respectively. The power received recorded in WDM-XGPON system high power than SCM-XGPON system. The 64-QAM modulation for SCM at $50 \mathrm{~km}$ record $-21.33 \mathrm{dBm}$ while the power received for WDM at $50 \mathrm{~km}$ is $-19.73 \mathrm{dBm}$.

The BER versus the length fiber when the input power is different ($2 \mathrm{dBm}, 2 \mathrm{dBm}$ and $6 \mathrm{dBm}$ ) for SCM-XGPON and WDM-XGPON system shows in Figs. 12 and 13 respectively. From the results, the BER increasing when the fiber distance been longer (from $10 \mathrm{~km}$ to $80 \mathrm{~km}$ ). Results for BER of WDM best of SCM when input power is different (- $2 \mathrm{dBm}, 2 \mathrm{dBm}$ and $6 \mathrm{dBm}$ ). The 64-QAM modulation for $\mathrm{SCM}$ at $50 \mathrm{~km}$ when input power is $6 \mathrm{dBm}$ the $\mathrm{BER}$ is $3.50 \times 10-15$ while for WDM at $50 \mathrm{~km}$ is $6.50 \times 10-17$. 


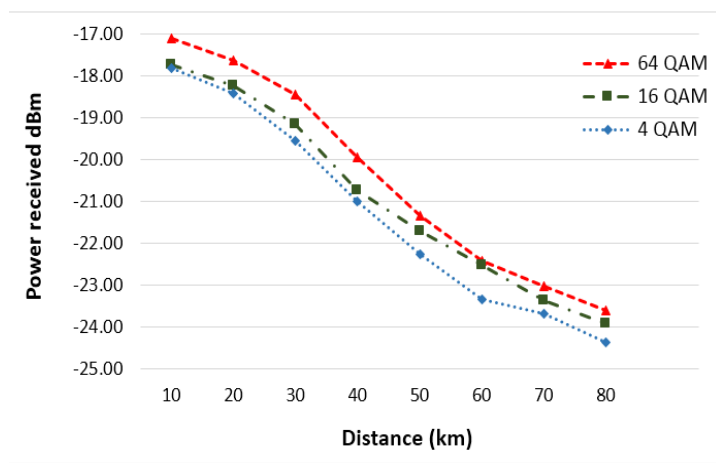

Figure 10. power received versus length of fiber for SCM-XGPON

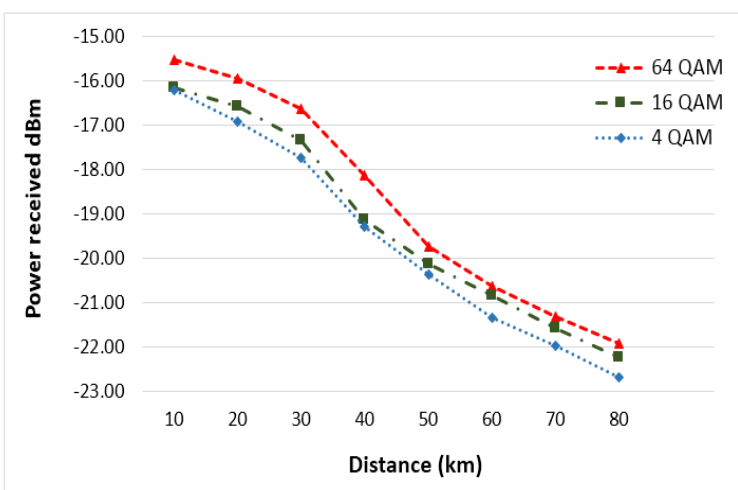

Figure 11. power received versus length of fiber for WDM-XGPON

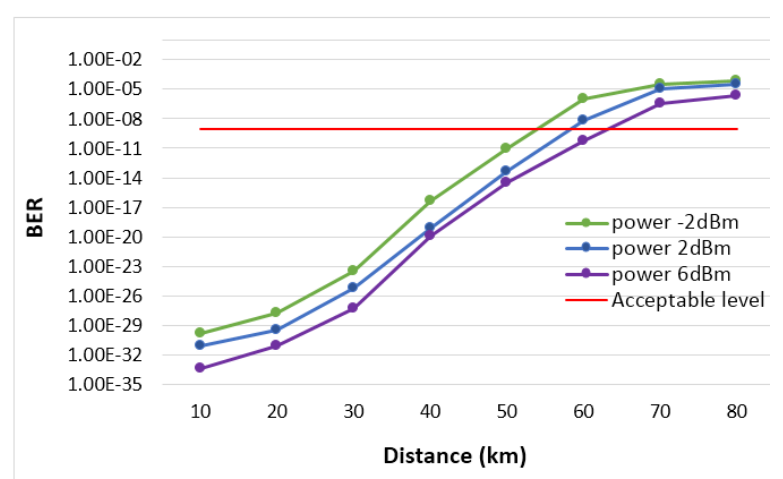

Figure 12. BER versus length of fiber for SCM-XGPON



Figure 13. BER versus length of fiber for WDM-XGPON
The quality factor for SCM-XGPON system and WDM-XGPON system shows in Figs. 14 and 15 respectively when the input power different $(-2 \mathrm{dBm}, 2 \mathrm{dBm}$ and $6 \mathrm{dBm})$. When increase the fiber the Quality factor decrease. The Quality factor for WDM greater than SCM. The 64QAM modulation for SCM at $50 \mathrm{~km}$ when input power is $6 \mathrm{dBm}$ the Q factor is 6.90 while for WDM is 8.10

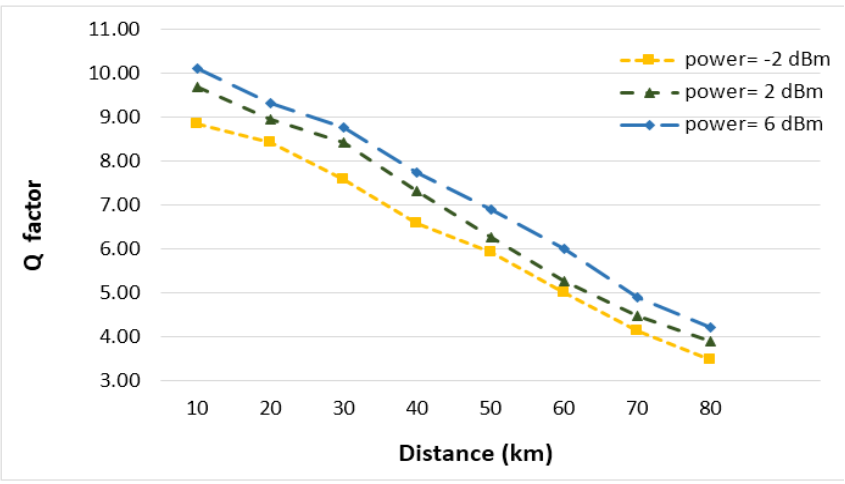

Figure 14. Quality factor versus length of fiber for SCM-XGPON

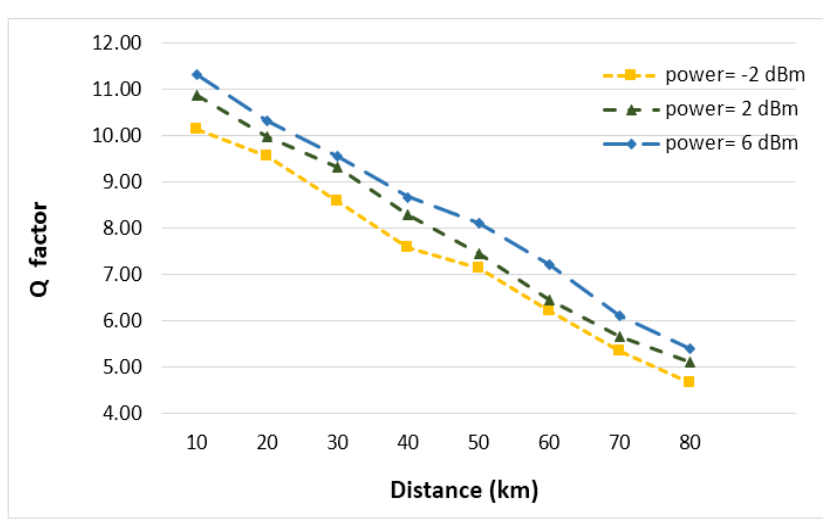

Figure 15. Quality factor versus length of fiber for WDM-XGPON

\section{CONCLUSION}

The XGPON combining it with the RoF system, which produces a system with very high efficient communication that uses the bandwidth effectively. Thus, the XGPON-ROF system possess better efficiency compared with the existing communication standards. In other words, combining between the XGPON and RoF will provides a robust communication by using the advantages of the optical fiber. In this paper, (WDM-XGPON) and (SCM-XGPON) were compared with (RoF) for constellation diagram, eye diagram, BER, power received, and Q-factor at different fiber length and at multi input power levels and use Three modulation schemes, such as; 4 - QAM, 16 - QAM and 64 - QAM. The eye diagram for WDM-XGPON open and clear is better than SCM-XGPON while power received for WDM-XGPON at $50 \mathrm{~km}$ is $-19.73 \mathrm{dBm}$ when power received for SCM-XGPON $-21.33 \mathrm{dBm}$ at the same distanceThe results for BER when input power $6 \mathrm{dBm}$ and modulation is 64-QAM at $50 \mathrm{~km}$ the WDM-XGPON $6.50 \times 10-17$ and the SCM-XGPON $3.50 \times 10-$ 15.The simulation results show that the system WDM-XGPON gives the best results from SCM-XGPON. In addition, with the increased of data with decrease the quality. Furthermore, increase in constellation points are illustrated in the constellation output as well. 


\section{REFERENCE}

[1] A. Zin, S. Idrus, N. Zulkifli, "The Characterization of Radio-over-Fiber Employed GPON Architecture for Wireless Distribution Network", International Journal of Machine Learning and Computing, vol. 1, no. 5, pp. 522-527, 2011.

[2] H. Al-Raweshidy and S. Komaki, "Radio over fiber technologies for mobile communications networks" Artech House, 2002.

[3] Arunava Seal, Samriddhi Bhutani, Sangeetha A " Performance Analysis of Radio over Fiber (RoF) System for Indoor Applications" 2017 International Conference on Technical Advancements in Computers and Communications.

[4] J. Salvador Asensi Pla, Ing. P. Reichert." DESIGN OF PASSIVE OPTICAL NETWORK" 2011.

[5] B. Mukherjee, "Optical WDM Networks", Springer Science + Business Media, Inc., 2006.

[6] M. Bakaul, "Technologies for DWDM Millimeter-Wave Fibre Radio Networks", Ph.D. Thesis, department of electrical and electronic engineering, University of Melbourne, Australia, January 2006.

[7] A. K. Vyas and N. Agrawal," Radio over Fiber: Future Technology of Communication", International Journal of Emerging Trends \& technology in computer science (IJETTCS), vol. 1, no. 2, pp. 233- 237, 2012.

[8] M. Arsat and S. M. Idrus," Performance Analysis of Sub carrier Multiplexed System for Radio over Fiber Technology", 2nd Malaysia Conference on Photonics, pp. 226 - 229, 2008.

[9] F. Grassi, "Experimental Evaluation of the Transmission in a Low Cost SCM/WDM Radio over Fibre System Employing Optical Broadband Sources and Interferometric Structures", 11th International Conference on Transparent Optical Networks, pp. 1 - 4, July 2009.

[10] A. Garadi, B. S. Bouazza, A. Bouarfa, and K. Meddah, "Enhanced Performances of SAC-OCDMA System by Using Polarization Encoding," J. Opt. Commun, pp. 1-6, 2018.

[11] Yehia Omar Urouq" Characterization of Radio Over Fiber Employed GPON Architecture for Different Modulation Schemes" The Islamic University of Gaza Graduate Studies - Faculty of Engineering Electrical Engineering Department 2014

[12] A.Q.Jumaah " A Review and Comprehensive Study of Wireless Channel in Mobile Communication System: Fading Phenomena and Estimation" Vol.11, no.2, PP.025-030, 2019.

[13] H. A. Leftah and H. L. Swadi " PERFORMA-NCE EVALUATION OF SINGLE CARRIER FREQUENCY

[14] DOMAIN EQUILIZER (SC-FDE) OVER IMPULSIVE NOISE CHANNEL" Vol .11, no .2, PP.273-277, 2018. 